\title{
THE MUCINOUS LAYER COVERING THE CORNEAL ENDOTHELIUM IN THE OWL STRIX ALÜCO*
}

\author{
BY \\ ERNST BÁRÁNY, LENNART BERGGREN, AND FRANTIŠEK VRABEC \\ From the Pharmacological Institute, University of Uppsala, Sweden, \\ and the First Eye Clinic, University of Prague, Czechoslovakia
}

\begin{abstract}
ABELSDORFF and Wessely (1909) reported the curious observation made in connexion with other work, that the aqueous humour of certain owls, Strix aluco (Syrnium aluco, Tawny owl), Athene noctua (Little owl), and Asio otus (Otus vulgaris, Long-eared owl), is slimy and highly viscous and easily spun into threads. On acidification with acetic acid, a ropy precipitate is formed. The part of the aqueous close to the cornea seemed to be the most viscous, since the first portion obtained often blocked the needle. In young birds, the aqueous was not slimy.

The findings of Abelsdorff and Wessely are interesting for two reasons. First, it is difficult to see how an adequate circulation of this viscous aqueous could take place. Secondly, the presence of so much mucinous substance in the aqueous of one group of birds is of interest in view of the presence of muco-polysaccharides of unknown origin in the outflow barrier of eyes with normal aqueous. We have therefore repeated and extended the observations of Abelsdorff and Wessely on the eye of Strix aluco.
\end{abstract}

\section{Methods}

Five tawny owls were obtained from dealers and other sources. They each weighed about $400 \mathrm{~g}$. Their age was not known. They were fed albino mice or rabbit meat.

In vivo observations of the eyes were made under anaesthesia with allylisopropylbarbituric acid, $\uparrow 50-60 \mathrm{mg}$. $/ \mathrm{kg}$. bodyweight given into the muscles of one leg. This dose induces a deep anaesthesia but allows full recovery. The observations were made with a Hamblin slit lamp and a Zeiss stereo-dissecting microscope $(\times 6$ to $\times 40)$.

For photographic purposes the living birds were unsuitable. Some experiments were therefore made with enucleated eyes. It turned out, however, that, because of the peculiar anatomy of the owl's eye, the process of enucleation caused an undesired mixing of the contents of the anterior chamber. Photographic experiments were therefore made with the eye in situ in the orbit. Some of these were done with the eye and its orbital cage immersed in saline in a cuvette of methylmethacrylate.

Viscosimetry was performed in microviscosimeters according to Cannon and Fenske (1938). The aqueous was diluted with barbital buffered saline, pH 7.2, containing a trace of diethyldithiocarbamate to remove heavy metals which might cause unspecific oxidative breakdown of hyaluronic acid after removal from the eye. The diluted aqueous was shaken for several hours and then centrifuged carefully. The enzyme used was a commercial staphylococcal hyaluronidase. $\ddagger$

\footnotetext{
* Received for publication October 26, 1956.

$\dagger$ Numal(R) Roche.

$\ddagger$ Hyason(R) from Organon, Oss, Holland.
} 
Fluorescent oil with a refractive index close to that of water was made by dissolving a minute amount of "Fluorescent Green H.W. 187 per cent." * in petroleum ether, boiling point $40-60^{\circ}$. The dye is completely insoluble in water and stays in the oil.

\section{Results}

Subjective Observations on Living Eyes of the Owl.-Observed with the slit lamp, the intact anterior chamber is optically empty. There is no suggestion of a vitreous-like structure.

Sodium fluorescein injected into a leg soon appears in the anterior chamber, but it takes a long time for the chamber to become homogeneously fluorescent. Fluorescent clouds form and change only very slowly. Obviously, mixing is a much slower process than in ordinary eyes.

If a needle is pushed through the limbus in the plane of the iris and the tip is brought into the pupillary area, one can see how the needle-tip carries along threads of previously invisible material. If small air-bubbles are injected into the anterior chamber with the eye facing up they rise quickly towards the cornea. The smallest ones do not rise all the way, however, but become stuck below the cornea, at an estimated depth of 4 to 5 corneal thicknesses. Larger air-bubbles rise further. The surface of the bubbles soon becomes visible as if some dust had accumulated upon it.

These findings confirm the impression of Abelsdorff and Wessely that there is a gradient of viscosity within the anterior chamber of the owl, the more viscous layer being closer to the cornea. It seemed possible therefore that the circulation of the aqueous takes place mainly close to the lens and iris. In order to test this possibility a small amount of Indian ink was deposited close to the centre of the pupil, by means of a fine needle through the limbus. The ink spread instantaneously like a thin sheet over the iris, extending to the chamber angle. Obviously, the fluid along the anterior surface of the iris is much more mobile than that close to the cornea. It can be mentioned that the surface of the black fluid appeared silvery white, as if something had condensed on it.

Photographic Experiments.-These were performed on dead birds, in one case on the morning on which the bird had been found dead in its cage, in the other cases shortly after killing by decapitation.

Into one eye, held with the vertex of the cornea upwards, a small amount of homogenized cream was injected into the posterior chamber through a needle introduced at the posterior pole of the eye. In the owl, this is accessible without enucleation. The cream appeared in the pupil but did not rise appreciably above the pupillary plane. Instead it spread laterally towards the chamber angle. Fig. 1 (opposite) shows this phase. Later, the cream spread into the bulk of the aqueous, but a clear space, impermeable to the cream, was visible close to the cornea with the slit lamp (Fig. 2, opposite). 


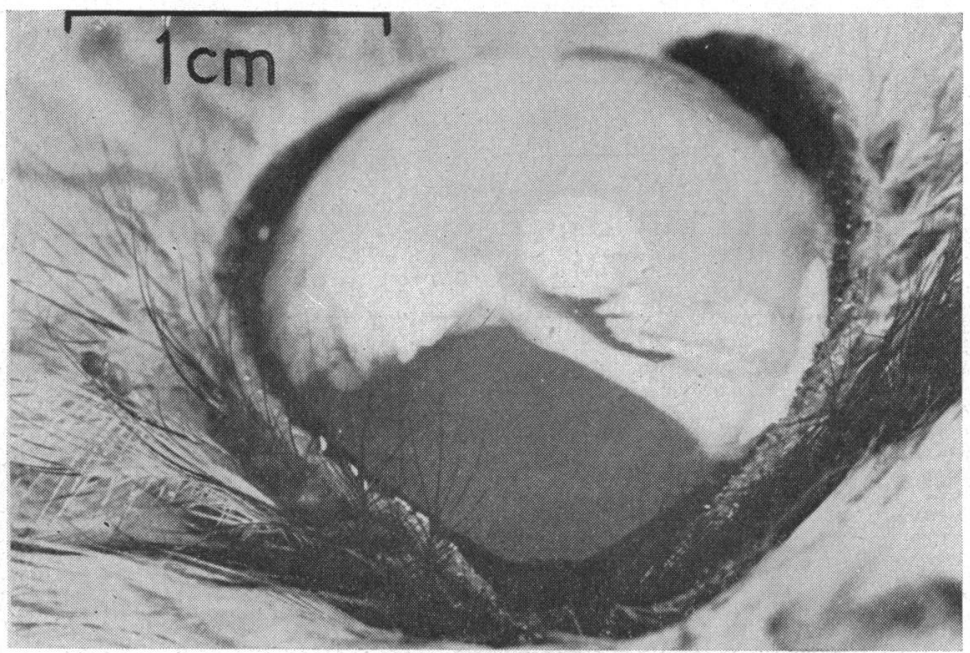

FIG. 1.-Eye of Strix aluco, with cream spreading over the surface of the iris from the pupil.

This experiment again shows that the aqueous close to the iris is much more fluid than that close to the cornea.

It was then attempted to photograph small air-bubbles introduced into the anterior chamber by a needle through the limbus. It was difficult, however, to obtain good outlines of air-bubbles. Therefore small drops of fluorescent oil were injected instead, by means of an Agla micrometric syringe. The eye was placed in the plastic cuvette with the cornea facing up, the slit lampwasarranged vertically above it, and photographs were taken through the sides of the cuvette. The beam of light was carefully adjusted so as to pass through the vertex of the oildrop. Fig. 3 shows a minute oil-drop in the mucinous layer coṿering the interior

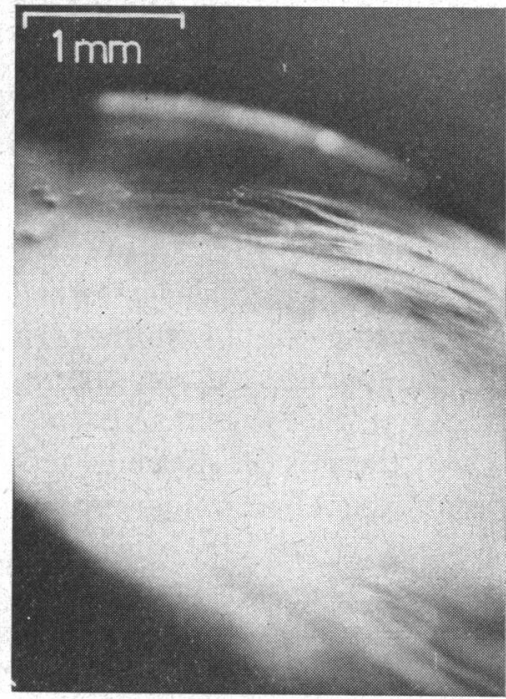

FIG. 2.-Eye of Strix aluco, showing how cream fails to mix with material beneath the cornea. Slit-lamp illumination, corneal section at top of picture.

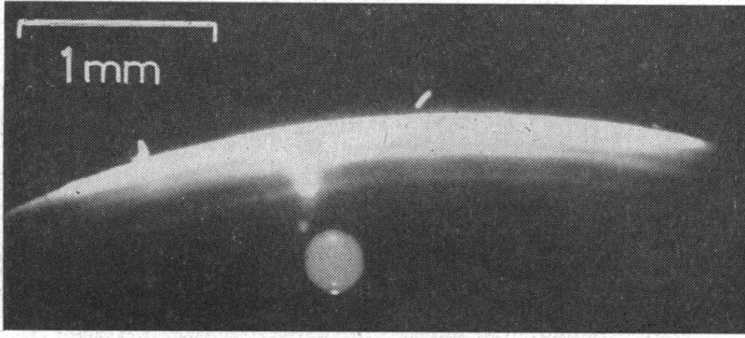

Fig. 3.-Eye of Strix aluco. Fluorescent oil-drop stuck in viscous material beneath cornea. Slit-lamp illumination, exposure 24 sec. 
surface of the cornea. In one of these experiments minute air-bubbles were accidentally introduced together with the oil-drop. Fig. 4 shows them suspended in "mid-aqueous".

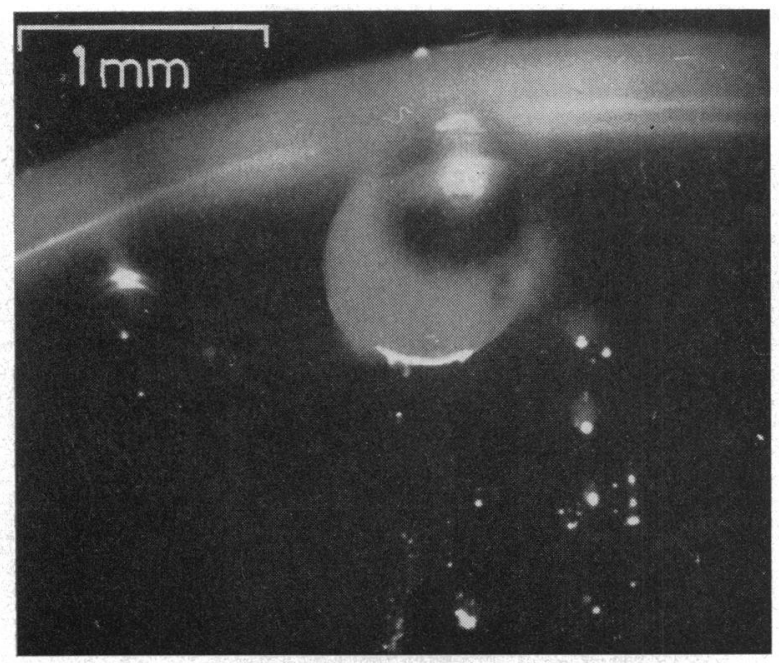

Fig. 4.-Eye of Strix aluco. Minute air-bubbles stuck in anterior chamber. Slit-lamp illumination, exposure $24 \mathrm{sec}$. Oil-drop and larger air-bubble visible close to cornea.

In vitro Observations on the Aqueous Humour of Owls. - Removal of the aqueous humour from the living eye by suction through a needle can be very difficult. In order to avoid admixture of vitreous humour, pressure was always exerted on the cornea during the aspiration. None the less and despite the use of a very coarse needle, no flow was obtained in one bird; in this case the aqueous formed what was practically an elastic jelly, from which threads $30-40 \mathrm{~cm}$. long could be pulled. A small part of this jelly rapidly liquefied when brought into contact with bacterial hyaluronidase. The rest of the jelly was dissolved in five times its volume of buffered saline containing a little diethyldithiocarbamate. The relative viscosity of this solution at $20^{\circ} \mathrm{C}$. was 1.60 and it remained stable for hours. On addition of 6 V.R.U./ml. Hyason ${ }^{(R)}$, the viscosity dropped to 1.08 in the course of one hour.

\section{Discussion}

We are able to confirm the statements of Abelsdorff and Wessely (1909). There is a mucinous substance in the aqueous of owls and it is most concentrated (or most highly polymerized) close to the cornea.

Our experiments indicate that the presence of mucin probably does not prevent the circulation of the aqueous, since the fluid close to the iris is much more mobile than that filling the anterior chamber. We have not obtained the impression, however, that there is a sharp boundary between a more mobile, central aqueous and a more viscous, peripheral one. Rather, the air-bubble and oil-drop experiments indicate a gradual transition. It would 
have been of interest to see how the viscous material is arranged in the vicinity of the trabecular meshwork, but this we were not able to study.

As to the nature of the mucinous substance, our enzyme experiment, using a highly specific, bacterial hyaluronidase, indicates that hyaluronic acid or a closely-related mucopolysaccharide is a main constituent. The marked capacity for thread formation indicates that the molecular weight is very high.

The mucinous substance could either be deposited from the aqueous or formed by the corneal endothelium. Abelsdorff and Wessely observed that the second aqueous of owls is not slimy, and concluded that "the mucin, adherent to the posterior surface of the cornea, probably belongs more to this latter than to the aqueous". The gradient of viscosity observed in our experiments is also most easily explained if the mucin is produced by the endothelium and gradually dissolved (and/or depolymerized) by the circulating aqueous. The production of a hyaluronic-acid containing mucus by mesodermal endothelium is in no way unique, the synovial fluid being a wellknown example.

As to the functional importance of the excessive amounts of mucin in the eyes of owls, one can only offer guesses. The anterior chamber of the owl's eye is relatively enormous (Fig. 5). If this volume had to be turned over at the same percentual rate as in other creatures, a very high rate of secretion of aqueous would be necessary. As it is, most of the aqueous is practically stagnant, and probably only the part in contact with the lens and iris is

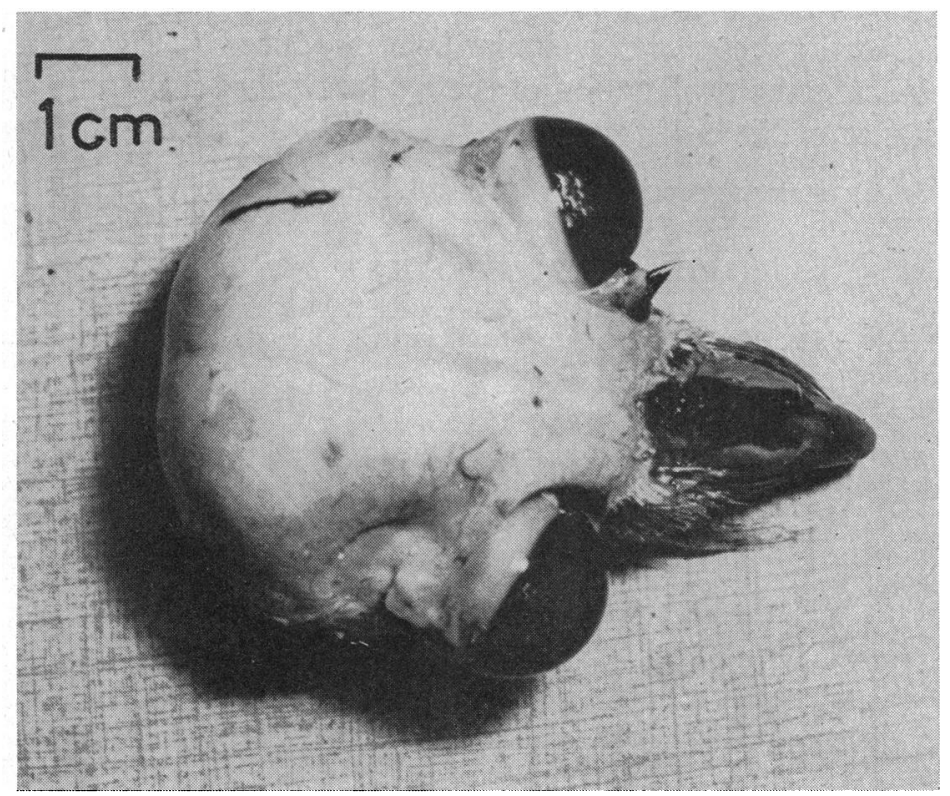

Fig. 5.-Head of Strix aluco, with skin removed, showing telescopic eyes. 
rapidly exchanged. Thus a certain economy could be effected. Another possible function is to make the cornea self-sealing.

It is improbable that the mucinous layer covering the endothelium in the eyes of owls should have no counterpart in other creatures. We have therefore looked for a similar hyaluronidase-sensitive coating, albeit on a more modest scale, on the corneal endothelium of several animals and birds. As yet we have not been able to prove its existence to our own satisfaction. There is, however, a hyaluronidase-sensitive coating on the trabeculae of birds and mammals (Vrabec, 1957; Berggren and Vrabec, 1957); since the endothelial cells covering the trabeculae are closely related to the corneal endothelium, it seems possible that this coating is analogous to that of the cornea in owls and that it too is produced locally. Its existence probably explains the hyaluronidase-sensitivity of the resistance of the chamber angle (Bárány, 1957).

\section{Summary}

The corneal endothelium in the Tawny owl (Strix aluco), is covered by a thick layer of a mucinous substance which can be removed and studied in vitro. The substance is depolymerized by bacterial hyaluronidase and consequently contains hyaluronic acid or a closely related mucopolysaccharide.

The viscosity of the mucinous layer decreases with the distance from the cornea, and the aqueous immediately in front of the lens and iris is of low viscosity.

It is believed that the mucinous substance is produced by the endothelial cells, and that the presence of a similar layer produced by the endothelium of the trabeculae is the explanation of the hyaluronidase-sensitivity of the outflow resistance of the chamber angle.

This work was supported by the Swedish Medical Research Council.

\section{REFERENCES}

Abelsdorf, G., and Wessely, K. (1909). Arch. Augenheilk., 64, Ergänzungsheft, p. 65.

BárÁNY, E. H. (1956). First Conference on Glaucoma.' Josiah Macy, Jr. Foundation, New York, 1956

BERGGReN, L., and VRABEC, F. (1957). Amer.J. Ophthal. In the press.

CANNON, M. R., and FENSKE, M. R. (1938). Industr. Engng Chem. (Anal. Ed.), 10, 297.

VRABEC, F. (1957). Amer. J. Ophthal. In the press. 